\title{
Distância morfológica entre genótipos de trigo com ausência e presença do caráter "stay-green"
}

\author{
Morphological distance among genotypes of wheat with absence and presence of the stay-green trait
}

\author{
José Antonio Gonzalez da Silva ${ }^{\mathrm{I}}$ Fernando Irajá Félix de Carvalho ${ }^{\mathrm{I}^{*}}$ Irineu Hartwig $^{\mathrm{I}}$ \\ Vanderlei da Rosa Caetano ${ }^{\mathrm{II}}$ Ivandro Bertan ${ }^{\mathrm{I}}$ Luciano Carlos da Maia ${ }^{\mathrm{I}}$ \\ Douglas André Mallmann Schimidt ${ }^{\mathrm{I}}$ Taciane Finatto $^{\mathrm{I}}$ Igor Pires Valério $^{\mathrm{I}}$
}

\section{RESUMO}

A estimativa da distância genética entre cultivares pode ser útil em um programa de melhoramento para o direcionamento de hibridações e no conhecimento do germoplasma disponível. O objetivo do presente trabalho foi o de estimar a distância genética entre as constituições genéticas de trigo adaptadas para a região Sul do Brasil de modo a apontar combinações promissoras com genótipos que expressam o caráter "stay-green". Foram avaliados 37 genótipos de trigo em campo experimental e mensurados quatorze caracteres morfológicos. Os métodos de agrupamento com base nas técnicas de Tocher, MDS e UPGMA foram eficientes para discriminar a distância genética entre os genótipos testados. O direcionamento de hibridações com linhagens de trigo do tipo de maturação "stay-green", de elevado potencial de rendimento, com cultivares elite pode fornecer populações promissoras na obtenção de genótipos superiores.

Palavras-chave: Triticum aestivum L., hibridação, variabilidade genética, técnicas de agrupamento, melhoramento de plantas.

\section{ABSTRACT}

Estimates of genetic distance among cultivars can be useful in an improvement program for directing crosses and evaluating the available germoplasm. This work was aimed at estimating the genetic distance among the genetic constitutions of wheat adapted in the South of Brazil in order to verify promising combinations with genotypes that express the staygreen trait. 37 wheat genotypes were evaluated in experimental field and measured fourteen morphological characters. The clustering methods based on the techniques of Tocher, MDS and UPGMA were efficient to discriminate the genetic distance among the tested genotypes. Directed crosses between high yield stay-green wheat lines and elite cultivars can provide promising populations for obtaining superior genotypes.
Keywords: Triticum aestivum L., hybridization, genetic variability, clustering techniques, plant breeding.

\section{INTRODUÇÃO}

Os estudos de dissimilaridade genética têm sido de grande importância em programas de melhoramento que envolvem hibridações, pois fornecem parâmetros para a identificação de genitores que possibilitem grande efeito heterótico na progênie e maior probabilidade de recuperação de genótipos superiores (CRUZ \& REGAZZI, 1997), visto que a heterose e a capacidade específica de combinação entre dois genitores dependem da existência de dominância no controle do caráter e da presença de dissimilaridade entre os genitores (FALCONER, 1987).

Os métodos preditivos da distância genética podem ser aplicados com base na avaliação morfológica do fenótipo da planta (CRUZ \& REGAZZI, 1997) ou por meio de dados moleculares, através do polimorfismo detectado em nível de DNA (OLIVEIRA, 1998; DINIZ-FILHO, 2000). Atualmente, estas técnicas têm sido amplamente utilizadas por inúmeros programas de melhoramento genético de diversas espécies vegetais (BENIN et al., 2002; BENIN et al., 2003), tendo como propósito selecionar genitores distantes geneticamente, que possibilitem maior efeito heterótico nas progênies com o propósito de recuperar recombinantes superiores em gerações segregantes. Desta forma, o emprego da estimativa de distância

\footnotetext{
'Departamento de Fitotecnia, Faculdade de Agronomia "Eliseu Maciel” (FAEM), Universidade Federal de Pelotas (UFPel). Campus Universitário, CP 354, 96010-900, Pelotas, RS, Brasil. E-mail: carvalho@ufpel.tche.br. * Autor para correspondência.

"Embrapa Clima Temperado (EMBRAPA/CPACT), Pelotas, RS, Brasil.
} 
genética possibilita selecionar genitores para a formação de populações de interesse para o melhoramento, assumindo que genótipos superiores e geneticamente dissimilares têm grande probabilidade de originarem populações com ampla variabilidade genética.

O trigo é originário de áreas com primaveras longas, temperatura média e baixa umidade relativa do ar. Entretanto, o Sul do Brasil revela clima com elevada umidade relativa e temperaturas variáveis, no período de cultivo desta espécie, proporcionando o favorecimento do desenvolvimento de moléstias, principalmente de parte aérea. Desta forma, o emprego do caráter "stay-green” é uma das possibilidades que poderá auxiliar o melhorista na obtenção de plantas mais produtivas, estáveis e com maior capacidade de adaptabilidade, pois a permanência verde da planta por um período mais prolongado de tempo até o enchimento de grãos poderá também auxiliar a planta de forma direta, no desenvolvimento de uma maior resistência à presença de moléstias (SILVA, 1999).

Estudando linhagens de trigo com e sem a presença do caráter “stay-green”, SILVA et al. (2003) observaram que genótipos portadores deste caráter apresentavam maior deposição de reservas na semente no período próximo a fase de maturação fisiológica, fase crítica no aumento do peso médio do grão, constituindo, desta forma, uma estratégia eficiente na potencialização da disponibilidade de assimilados para a espiga e, conseqüentemente, no incremento do rendimento de grãos. Além disso, este caráter têm sido relatado por apresentar uma associação positiva com resistência ao acamamento, resistência à moléstias e expressiva tolerância ao frio e ao calor (WALULU et al., 1994; CUKADAR-OLMEDO \& MILLER, 1997; SILVA et al., 2003), podendo permitir maior estabilidade de produção, principalmente em anos em que as condições de ambiente são desfavoráveis.

O objetivo do presente trabalho foi o de estimar a distância genética entre as constituições genéticas de trigo adaptadas para a região Sul do Brasil, de modo a apontar combinações promissoras com genótipos que expressam o caráter "stay-green”.

\section{MATERIAL E MÉTODOS}

As linhagens do tipo de maturação "staygreen” e sincronizado foram obtidas a partir dos anos de 1999 a 2002 pelo avanço de gerações do cruzamento entre a linhagem de trigo TB188 (maturação sincronizada) com TB438 ("stay-green”). Foram obtidas linhagens com ausência e presença do caráter "staygreen” (FG = linhas “stay-green” e FZ = linhas com maturação sincronizada). Além disso, foram obtidos retrocruzamentos um e dois, respectivamente $\mathrm{RC}_{1} \mathrm{~F}_{1}\left(\mathrm{P}_{1}\right.$ $\left.\mathrm{x} \mathrm{F}_{1}\right)$ e $\mathrm{RC}_{2} \mathrm{~F}_{1}\left(\mathrm{P}_{2} \times \mathrm{F}_{1}\right)$; autofecundados até atingirem a homozigose, quando foram selecionadas plantas para a presença $\left(\mathrm{RC}_{1} \mathrm{G}\right.$ e $\left.\mathrm{RC}_{2} \mathrm{G}\right)$ e ausência do caráter "staygreen ( $\mathrm{RC}_{1} \mathrm{Z}$ e $\left.\mathrm{RC}_{2} \mathrm{Z}\right)$ ".

No presente estudo, foram avaliados 37 genótipos de trigo, sendo cinco cultivares ("BRS179”, “BRS177”, “EMBRAPA40”, “BR23” e “CEP27”) e 32 linhagens (15 linhagens “stay-green” e 17 de maturação sincronizada).

Para a mensuração dos caracteres morfológicos, foram conduzidos experimentos nas safras agrícolas de 2003 e 2004, na área experimental do Centro de Genômica e Fitomelhoramento da Universidade Federal de Pelotas (CGF/UFPel), no município de Capão do Leão-RS. O município está situado a $31^{\circ} 52^{\prime} 00^{\prime \prime}$ de latitude sul e $52^{\circ} 21^{\prime} 24^{\prime \prime}$ de longitude oeste, a uma altitude de $13,24 \mathrm{~m}$. O delineamento experimental empregado foi o de blocos completos casualizados com três repetições, sendo as parcelas compostas por cinco fileiras de $3 \mathrm{~m}$ de comprimento e com espaçamento de $0,20 \mathrm{~m}$ entre filas. A adubação de base foi de $300 \mathrm{~kg} \mathrm{ha}^{-1}$ de NPK (5-20-20) e mais $60 \mathrm{~kg} \mathrm{ha}^{-1}$ de nitrogênio aplicado no início do afilhamento. O controle das invasoras foi realizado com herbicida e capina manual quando necessário, e o controle de pragas e moléstias realizado de acordo com as indicações técnicas da cultura (CSBPT, 2004).

Foram avaliados 14 caracteres morfológicos, segundo os procedimentos apresentados por SCHEEREN (1984): dias da emergência ao florescimento (DEF); dias da emergência à maturação (DEM); dias do florescimento à maturação (DFM); estatura de planta em cm (EP), medida do solo até o final da espiga, excluindo as aristas; número de afilhos férteis por metro linear (AFML); peso de mil grãos em g (PMG); peso do hectolitro em $\mathrm{kg} \mathrm{hL}^{-1}(\mathrm{PH})$; rendimento de grãos em $\mathrm{kg}$ $\mathrm{ha}^{-1}$ (RG). Além disso, por meio da colheita de 10 espigas de cada parcela, foram avaliados os caracteres: comprimento da espiga em cm (CE), número de espiguetas por espiga (NEE), peso de espiga em g (PE), número de grãos por espiga (NGE), peso de grãos por espiga (PGE) e peso de palha da espiga (PLH). Os dados dos caracteres morfológicos foram submetidos à análise de variância, considerando-se os efeitos de genótipos e dos anos como fixos. Posteriormente, com base nas médias dos caracteres avaliados nos dois anos, foi estimada a distância generalizada de Mahalanobis ( $\left.\mathrm{D}^{2}\right)$ entre todos os pares de genótipos, por meio do programa computacional Genes (CRUZ, 2001). Com base na matriz de distância genética: i) foi empregado o método de agrupamento de Tocher, utilizando o programa computacional Genes (CRUZ, 2001); ii) foi 
construído um dendrograma utilizando o método de agrupamento da distância média (UPGMA), sendo que o ajuste entre a matriz de distâncias e o dendrograma foi estimado pelo coeficiente de correlação cofenética (r; SOKAL \& ROHLF, 1962), por meio do programa computacional NTSYS pc 2.1 (ROHLF, 2000); e iii) fezse análise de escala multidimensional (MDS), para projeção das distâncias em um plano bidimensional. A eficiência desta projeção das distâncias em um plano bidimensional foi estimada a partir da correlação entre as distâncias originais (Dij) e as representadas nos gráficos (Doij), sendo estimado, também, o nível de estresse (S), que mede o ajuste entre a distância na configuração bidimensional (Doij) e a distância original (Dij), do seguinte modo:

$$
\mathrm{S}=\sqrt{\frac{\sum_{i<} \sum_{j}(\text { Doij }- \text { Dgij })^{2}}{\sum_{i<} \sum_{j} D^{2} o i j}}
$$

Estas análises foram realizadas com o auxílio do programa computacional NTSYS pc 2.1 (ROHLF, 2000).

\section{RESULTADOS E DISCUSSÃO}

Por meio da análise dos quadrados médios para as fontes de variação de genótipo, ano e interação genótipo $\mathrm{x}$ ano (Tabela 1), foi possível constatar a presença de diferenças significativas em todas as variáveis avaliadas, exceto para os caracteres PGE, NEE, PLH, AFML, DEF e DFM na interação genótipo $x$ ano. A significância observada em todos os caracteres no fator genótipo representa um indicativo de que as constituições genéticas apresentam comportamento distinto entre os caracteres morfológicos avaliados, viabilizando, desta forma, o emprego de estudos de distância genética. Entretanto, a significância verificada da interação genótipo $\mathrm{x}$ ano revela a impossibilidade de analisar métodos de distância dentro de cada ano separadamente, visto que as respostas encontradas levariam à inconsistência dos resultados. Dessa forma, há necessidade de avaliar os genótipos de forma conjunta, considerando-se os dois anos, visto que o incremento no número de anos para avaliação determina uma maior segurança nos resultados. Contudo, também é possível verificar uma elevada precisão experimental do trabalho, uma vez que os coeficientes de variação foram de reduzida magnitude, variando de 1,1 a $15,8 \%$ para DEM e AFLM, respectivamente.

Na tabela 2, pode ser visualizado que o método de agrupamento de Tocher possibilitou a divisão dos 37 genótipos testados em quatro grupos distintos. Este método promove um arranjo de grupos de modo que exista homogeneidade dentro do grupo e heterogeneidade entre grupos formados. Dessa forma, os grupos obtidos representam valiosa informação na escolha de genitores para o melhorista, visto que as

Tabela 1 - Resumo das análises de variância para os quatorze caracteres utilizados para estimar a distância genética entre 37 cultivares de trigo. FAEM/UFPEL, Pelotas, 2005.

\begin{tabular}{|c|c|c|c|c|c|c|}
\hline \multirow{2}{*}{ Caracteres } & \multicolumn{4}{|c|}{ Quadrado médio } & \multirow{2}{*}{ Média } & \multirow{2}{*}{ CV (\%) } \\
\hline & Genótipo (G) & Anos (A) & $\mathrm{G} \times \mathrm{A}$ & Erro & & \\
\hline RG & $840821 *$ & $11714837 *$ & $265667 *$ & 63201 & 2221.8 & 11.3 \\
\hline $\mathrm{PH}$ & $7.7^{*}$ & $720.0 *$ & $4.9^{*}$ & 2.7 & 74.0 & 2.2 \\
\hline PGE & $0.2^{*}$ & $2.3^{*}$ & $0.1^{\mathrm{ns}}$ & 0.1 & 2.0 & 13.3 \\
\hline CE & $5.2^{*}$ & $81.1^{*}$ & $0.9 *$ & 0.6 & 11.1 & 7.2 \\
\hline NEE & $12.6^{*}$ & $109.6^{*}$ & $1.9^{\mathrm{ns}}$ & 1.2 & 19.9 & 5.7 \\
\hline NGE & $210.2^{*}$ & $1478.9 *$ & $63.2^{*}$ & 36.0 & 54.9 & 10.9 \\
\hline $\mathrm{PE}$ & $0.6^{*}$ & $0.7 *$ & $0.1^{*}$ & 0.1 & 2.9 & 11.3 \\
\hline PLH & $0.2^{*}$ & $0.4^{*}$ & $0.1^{\mathrm{ns}}$ & 0.1 & 0.8 & 13.6 \\
\hline PMG & $35.2 *$ & $469.4^{*}$ & $39.1^{*}$ & 11.2 & 34.9 & 9.5 \\
\hline AFML & $337.1^{*}$ & $15617.3^{*}$ & $140.6^{\mathrm{ns}}$ & 149.3 & 61.6 & 15.8 \\
\hline DEF & $34.1^{*}$ & $198.6^{*}$ & $2.2^{\mathrm{ns}}$ & 2.0 & 89.8 & 1.6 \\
\hline DFM & $62.3^{*}$ & $69.2^{*}$ & $3.2^{\mathrm{ns}}$ & 4.7 & 42.74 & 5.0 \\
\hline DEM & $113.5^{*}$ & $502.5^{*}$ & $4.0 *$ & 2.4 & 132.5 & 1.1 \\
\hline $\mathrm{EP}$ & $333.8^{*}$ & $11603.7 *$ & $33.4^{*}$ & 11.5 & 79.1 & 4.3 \\
\hline
\end{tabular}

* significativo a 5\% de probabilidade de erro pelo teste F; Caracteres: RG = rendimento de grãos; $\mathrm{PH}=$ peso do hectolitro; $\mathrm{PGE}=$ peso de grãos por espiga; $\mathrm{CE}$ = comprimento da espiga; NEE = número de espiguetas por espiga; NGE = número de grãos por espiga; $\mathrm{PE}=$ peso de espiga; $\mathrm{PLH}$ = peso de palha da espiga; $\mathrm{PMG}$ = peso de mil grãos; $\mathrm{AFML}$ = número de afilhos férteis por metro linear; $\mathrm{DEF}=$ dias da emergência à floração; DFM = dias do florescimento à maturação; DEM = dias da emergência à maturação e EP = estatura de planta. 
Tabela 2 - Agrupamento dos 37 genótipos de trigo pelo método de agrupamento de Tocher, utilizando a distância generalizada de Mahalanobis como medida de distância genética. CGF/UFPEL, Pelotas, 2005.

\begin{tabular}{ll}
\hline Grupos & \multicolumn{1}{c}{ Genótipos } \\
\hline I & G30, G39, G47, G53, G65, G71, G74, RC1G32, RC2G34, RC2G40, RC2G46, RC2G54, RC2G62, RC2G67, Z31, Z37, \\
II & Z49, Z57, Z69, RC1Z43, RC1Z45, RC1Z55, RC1Z58, RC1Z68, RC1Z72, RC1Z76 e RC2Z61 \\
III & RC2Z35, RC2Z42, TB188 e RC2Z56 \\
IV & BRS179, BRS177, BR23, EMBRAPA40 e CEP27 \\
\hline
\end{tabular}

novas populações a serem formadas deverão estar baseadas na magnitude de suas distâncias e no potencial por si só dos genitores. Pode ser verificado que o grupo I de Tocher reuniu o maior número de genótipos (G30, G39, G47, G53, G65, G71, G74, RC G32, RC $\mathrm{G}_{2} 4, \mathrm{RC}_{2} \mathrm{G} 40, \mathrm{RC}_{2} \mathrm{G} 46, \mathrm{RC}_{2} \mathrm{G} 54, \mathrm{RC}_{2} \mathrm{G} 62, \mathrm{RC}_{2} \mathrm{G} 67, \mathrm{Z31}$, Z37, Z49, Z57, Z69, RC Z43, RC Z45, RC Z55, RC Z58, RC $\mathrm{Z}_{1} 68, \mathrm{RC}_{1} \mathrm{Z72}$, RC $\mathrm{ZZ}_{1} 76$ e $\mathrm{RC}_{2} \mathrm{Z61}$ ), sugerindo que estas constituições genéticas apresentam entre si menor distância fenotípica. Neste grupo I, pode ser encontrada a presença de todas as linhagens portadoras do gene “stay-green”, ao contrário da TB438 (genitor com presença do caráter), que foi incluída no grupo IV, devido, possivelmente, à contribuição da reduzida estatura de planta apresentada por este genótipo em comparação aos demais (dados não apresentados).

No grupo II, estão incluídas as quatro linhagens que evidenciam comportamento sincronizado $\left(\mathrm{RC}_{2} \mathrm{Z35}, \mathrm{RC}_{2} \mathrm{Z} 42, \mathrm{RC}_{2} \mathrm{Z} 56\right.$ e o genitor TB188, que manifesta ausềncia do caráter “stay-green”). De modo geral, estes resultados indicam a possibilidade de utilização destas linhas-irmãs em hibridações com genótipos do grupo I que evidenciam comportamento de permanência verde, possibilitando, desta forma, a recuperação de constituições genéticas com este padrão genotípico, reunindo em um único genótipo alelos favoráveis, que são expressados nos dois genitores.

Caracteres agronômicos distintos evidenciados pela formação tanto do primeiro como do segundo grupo também são esperados nas cultivares “BRS179”, “BRS177”, “BR23”, “EMBRAPA40” e “CEP27” pela formação do terceiro grupo (Tabela 2), com possibilidade de êxito na indicação de linhagens "stay-green” em cruzamentos com estas constituições genéticas, visto que representam elevado potencial de rendimento aliado a características intrínsecas de cada cultivar, que podem ser de interesse específico do melhorista no momento da escolha de genitores para cruzamento. Contudo, além dos distintos grupos de genótipos evidenciados, apenas este parâmetro pode não fornecer subsídios consistentes que, permitam ao melhorista segurança na escolha das melhores combinações, o que demonstra a necessidade de que os genótipos destinados a hibridações, além dos distintos grupos formados, apresentem também elevado potencial de rendimento de grãos. Dessa forma, a possibilidade de seleção de genótipos transgressivos, devido à ocorrência de heterose e à ação de genes complementares, pode ser fortalecida, devido à expectativa de que constituições genéticas de elevado rendimento, porém distantes geneticamente, apresentem locos distintos controlando o caráter e, conseqüentemente, determinando boa capacidade de combinação (CARVALHO et al., 2001).

Analisando a figura 1, obtida através do método de agrupamento UPGMA, utilizando Mahalanobis como medida de distância, ficou fortemente evidenciada a presença de três grandes grupos. Todas as linhagens com e sem a presença do caráter "stay-green" formaram um grupo distinto, à exceção da linhagem TB438, que permaneceu isolada das cinco cultivares-elite empregadas no experimento. O agrupamento dos genótipos pelo método UPGMA apresentou-se como similar ao método de Tocher quando da formação de grupos entre genótipos mais divergentes. Entretanto, apenas não permitiu incluir os genótipos TB188, RC Z35, RC Z42 e RC Z56 como conjunto distinto em relação aos demais genótipos. Contudo, o coeficiente de correlação cofenética de 0,80 revelou um bom ajuste entre a representação gráfica das distâncias no dendrograma e a sua matriz original (ROHLF, 2000), possibilitando a realização de inferências por meio da análise visual da figura 1. A presença dos três grupos formados, principalmente entre linhagens "stay-green” e as cinco cultivares empregadas no estudo, representa promissor conjunto de genótipos de possibilidade de êxito se empregados em cruzamentos, desde que levando também em consideração o comportamento do rendimento de grãos. Portanto, no caso de cruzamentos entre genótipos-elite (também denominados de "adaptado $x$ adaptado” ou "bom x bom”), os melhoristas de trigo

Ciência Rural, v.37, n.5, set-out, 2007. 




devem prender forte atenção na escolha correta de bons genitores, a fim de direcionar seus esforços na seleção de plantas com base em populações de elevada frequência de alelos favoráveis.

Na figura 2, referente à representação das distâncias em gráfico bidimensional da escala multidimensional (MDS), os genótipos evidenciaram o mesmo comportamento entre esta técnica de agrupamento e a UPGMA (Figura 1), confirmando, portanto, a forte distinção dos grupos de genótipos formados. É importante ressaltar que os procedimentos de agrupamento compararam todos os pares de indivíduos através de medidas de dissimilaridade, porém a análise de MDS se diferencia dos demais por procurar o maior ajuste entre a matriz original de distâncias por meio de uma análise de regressão. $\mathrm{O}$ ajuste realizado é comparado com a distância original, sendo então determinado o coeficiente de estresse, de forma a inferir sobre a confiabilidade dos resultados (Figura 2). O coeficiente de estresse determinado foi de 0,08 , indicando elevada confiabilidade na representação das distâncias entre os genótipos avaliados.

A elevada concordância entre as técnicas MDS e UPGMA (Figuras 1 e 2) e o auxílio do agrupamento pela técnica de Tocher na discriminação dos genótipos mais divergentes forneceram subsídios para a realização de inferências mais seguras a respeito da distância entre os genótipos avaliados. Dessa forma, foi possível inferir que as linhagens do grupo "stay-green” e sincronizado apresentam entre si reduzida distância genética, pelo forte agrupamento obtido nestas constituições genéticas. Porém, essas linhagens são fortemente distintas do grupo originado pelas cultivares "BRS177”, "BRS179”, “BR23”, “EMBRAPA40” e “CEP27” e da linhagen TB438, que

Ciência Rural, v.37, n.5, set-out, 2007. 


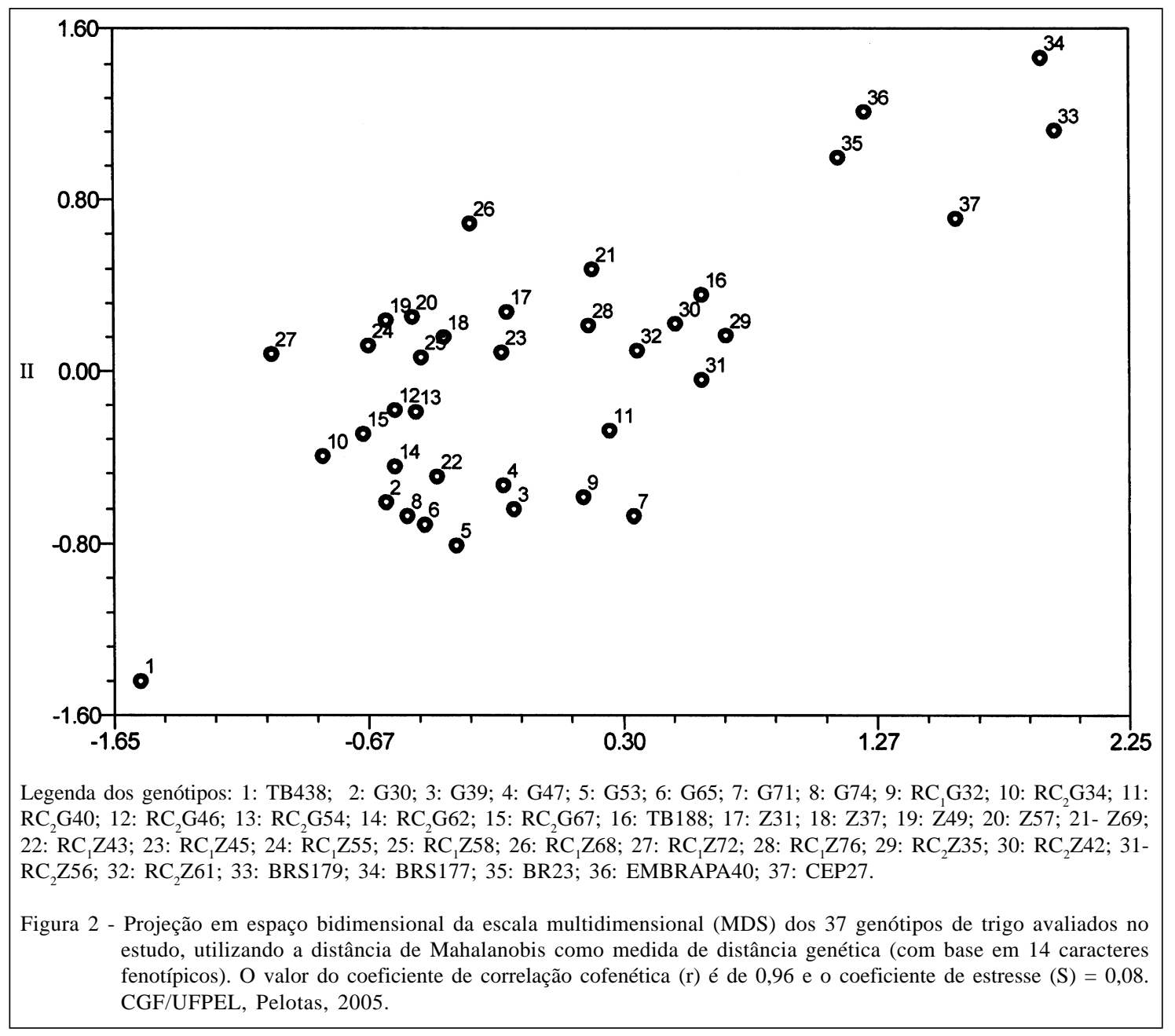

expressou comportamento isolado em relação aos demais. Portanto, fica evidente a possibilidade de hibridação levando em consideração os genótipos dos distintos grupos formados.

\section{CONCLUSÃO}

Os métodos de agrupamento com base nas técnicas de Tocher, MDS e UPGMA são eficientes para discriminar a distância genética entre os genótipos testados.

O direcionamento de hibridações com linhagens de trigo do tipo de maturação "stay-green”, de elevado potencial de rendimento com cultivares elite, fornecem populações promissoras na obtenção de genótipos superiores.

\section{AGRADECIMENTOS}

Os autores agradecem à Coordenação de Aperfeiçoamento de Pessoal de Nível Superior (CAPES), ao Conselho Nacional de Desenvolvimento Científico e
Tecnológico $(\mathrm{CNPq})$ e à Fundação de Amparo à Pesquisa do Estado do Rio Grande do Sul (FAPERGS), pela concessão de bolsas de Pós-graduação, Iniciação Científica e suporte nesta pesquisa.

\section{REFERÊNCIAS}

BENIN, G. et al. Comparações entre medidas de dissimilaridade e estatísticas multivariadas como critérios no direcionamento de hibridações em aveia. Ciência Rural, v.33, n.4, p.657662, 2003.

BENIN, G. et al. Identificação da dissimilaridade genética entre genótipos de feijoeiro comum (Phaseolus vulgaris L.) do grupo preto. Revista Brasileira de Agrociência, v.8, n.3, p.179184, 2002.

CARVALHO, F.I.F et al. Estimativas e implicações da herdabilidade como estratégia de seleção. Pelotas: UFPel, 2001. 99p.

COMISSÃO SUL BRASILEIRA DE PESQUISA DE TRIGO. Recomendações da Comissão Sul-Brasileira de Pesquisa de Trigo. Passo Fundo: EMBRAPA-CNPT, 2004. 74p.

CRUZ, C.D.; REGAZZI, A.J. Modelos biométricos aplicados ao melhoramento genético. Viçosa: UFV, 1997. 390p. 
CRUZ, C.D. Programa genes: aplicativo computacional em genética e estatística. Viçosa: UFV, 2001. 648p.

CUKADAR-OLMEDO, B.; MILLER, J.F. Inheritance of the stay-green trait in sunflower. Crop Science, v.37, n.1, p.150153, 1997.

DINIZ-FILHO, J.A.F. Métodos filogenéticos comparativos. Ribeirão Preto: Holos, 2000. 162p.

FALCONER, D.S. Introdução à genética quantitativa. Viçosa: UFV, 1987. 279p.

OLIVEIRA, A.C. Construção de mapas genéticos em plantas. In: MILACH, S.C.K. (Ed). Marcadores de DNA em plantas. Porto Alegre: UFRGS, 1998. 141p.

ROHLF, F.J. NTSYS-pc: numerical taxonomy and multivariate analysis system, version 2.1. New York: Exeter Software, 2000. 83p.
SCHEEREN, P.L. Instruções para utilização de descritores de trigo (Triticum sp.) e triticale (Triticun sp.). Passo Fundo: EMBRAPA-CNPT, 1984. 32p. (Documentos, 9).

SILVA, S.A. et al. Enchimento de sementes em linhas quase isogênicas de trigo com presença e ausência do caráter "staygreen”. Pesquisa Agropecuária Brasileira, v.38, n.5, p.613618, 2003.

SILVA, S.A. Estimativa da herança do caráter "stay-green" em genótipos de trigo hexaplóide. 1999. 56f. Dissertação (Mestrado em Sementes) - Curso de Pós-graduação em Sementes, Universidade Federal de Pelotas.

SOKAL, R.R.; ROHLF, F.J. The comparison of dendrograms by objective methods, Taxon, v.11, n.2, p.33-40, 1962.

WALULU, R.S. et al. Inheritance of the stay green trait in sorghum. Crop Science, v.34, n.4, p.970-972, 1994. 